\title{
Penerapan Principal Component Analysis untuk Mereduksi Dimensi Data Penerapan Teknologi Informasi dan Komunikasi untuk Pendidikan di Sekolah
}

\author{
Diah Wulandari ${ }^{\mathrm{a}, *}$, Toni Prahasto ${ }^{\mathrm{b}}$, Vincencius Gunawan ${ }^{\mathrm{c}}$ \\ a PUSTEKKOM Kementerian Pendidikan dan Kebudayaan \\ ${ }^{\mathrm{b}}$ Fakultas Teknik, Universitas Diponegoro \\ ${ }^{\mathrm{c}}$ Fakultas Sains dan Matematika, Universitas Diponegoro
}

Naskah Diterima : 21 April 2016; Diterima Publikasi : 11 Juli 2016

DOI: 10.21456/vol6iss2pp91-96

\begin{abstract}
This study aimed to analyze the most influential variable in the implementation of ICT in schools. Principal component analysis using linear algebra to reduce the dimension of data with variables that are interconnected into a new set of data with variables that are not related to each other, called the principal component. Principal component is used to save and calculate how much correlation within varian. The ICT data is collected from 50 schools, this data is grouped into five group based on reference domain of ICT for education indicator by UIS 2009. Dataset per group is used as input for principal component analysis algorithm with Matlab R2014a and produce principal component. Principal component analysis produce five variable with the most influence based on their domain, there are mean hour for individual using of ICT in curicculum domain, existence school in internet in infrastructure domain, learner proportion in using computer laboratory for learning in teacher development domain, learner propostion that computer basic skill course in participation domain.
\end{abstract}

Keywords: ICT; Principal component analysis; Dataset

Penelitian ini ditujukan untuk melakukan analisa variable yang paling berpengaruh dalam implementasi TIK untuk pendidikan di sekolah. Principal Component Analysis menggunakan aljabar linear untuk mereduksi dimensi data dengan variable yang saling berhubungan menjadi data set baru dengan variable yang tidak saling berkaitan, yang disebut dengan principal component. Principal component digunakan untuk menyimpan dan menghitung nilai korelasi antar varian. Data TIK sekolah dikumpulkan melalui pengisian kuisioner dari 50 sekolah, data tersebut kemudian dikelompokan menjadi lima kelompok berdasarkan referensi domain TIK untuk pendidikan dari UIS 2009. Dataset dari masing-masing kelompok tersebut digunakan sebagai input untuk algoritma PCA menggunakan Matlab R2014a dan menghasilkan principal component. Analisa principal component menghasilkan lima variable yang paling berpengaruh pada masing-masing domain, yaitu rata-rata jumlah jam penggunaan TIK individu dalam kurikulum), eksistensi sekolah di internet melalui website sekolah berupa infrastruktur, ketersediaan layanan pendukung TIK untuk pengembangan guru), proporsi siswa yang menggunakan labortorium komputer untuk pembelajaran dalam domain pemanfaatan, proporsi siswa yang mengikuti mata pelajaran skill komputer dasar dalam domain partisipasi siswa.

Kata Kunci: TIK; Principal component analysis; Dataset

\section{Pendahuluan}

Teknologi Informasi dan Komunikasi (TIK) merupakan teknologi dibidang informasi dan komunikasi berbasis elektronika yang digunakan untuk pengambilan, pengumpulan, pengolahan, penyimpanan, penyebaran, dan penyajian data, informasi dan konten (Kemdikbud, 2013). TIK dalam pendidikan mempunyai peranan yang sangat penting

*) Penulis korespondensi: diah.wulandari@kemendikbud.go.id untuk perluasan akses, menekan biaya dan meningkatkan kualitas pendidikan (UIS, 2014).

TIK terbukti mampu meningkatkan konsentrasi siswa dengan membuat kegiatan pembelajaran lebih menyenangkan sehingga dapat meningkatkan hasil belajar dan perilaku siswa (Hussain et al., 2011). Guru menggunakan keterampilan TIK untuk menyiapkan lesson plan tiap materi, mencari sumber belajar, membuat presentasi/menyampaikan materi menggunakan media digital, dan proses belajar 
mengajar sehingga lebih menyenangkan bagi siswa (Umar dan Yusoff, 2014).

Life long learning dianggap sebagai salah satu kunci keberhasilan pendidikan dengan mengembangkan potensi dan kreatifitas dari semua individu baik siswa maupun guru (active learning) yang didukung sejumlah instruksi yang melibatkan kelompok siswa untuk mencapai tujuan akademis (collaborative learning) (Pinhero dan Simoes, 2012). Aktifitas kolaborasi dapat membentuk social skill siswa, contohnya kemampuan berpikir kritis dan saling menghargai pendapat dengan anggota kelompok lainnya dalam menyelesaikan tugas untuk subyek tertentu melalui media digital, selain itu hal ini juga memudahkan penyimpanan dan berbagi bahan belajar. Di sisi lain, TIK membantu guru dalam memberikan pemahaman siswa pada materi tertentu melalui tugas kelompok melalui collaborative learning dan dengan mudah melakukan evaluasi berdasarkan aktifitas tiap anggota kelompok yang terekam pada history class (Valcarel, et al., 2014).

Pengukuran TIK dalam pendidikan perlu dilakukan karena meningkatnya permintaan data TIK dalam pendidikan sebagai informasi dasar statistik pendidikan yang mendukung kebijakan TIK dalam pendidikan (UIS, 2014). Kebijakan TIK dalam pendidikan digunakan untuk memberikan layanan TIK dalam bentuk data, informasi, konten, aplikasi, infrastruktur, dan sumber daya manusia (Kemdikbud, 2013). Indikator yang digunakan untuk mengukur kemajuan TIK di sektor pendidikan telah dikembangkan oleh UNESCO Institute for Statistics (UIS) (ITU, 2010) dan dijabarkan dalam Guide to Measuring Information and Communication Technologies (ICT) in Education (UIS, 2009). Indikator tersebut telah diadopsi dan digunakan pada beberapa penelitian, antara lain analisa faktor yang mempengaruhi indeks gabungan TIK pada tingkat sekolah dasar dan menengah menggunakan metode Analytic Hierarchy Process (AHP) (Aoki et al., 2013) dan penelitian tentang perbandingan analisis perbandingan statistik data agregat sekolah setiap negara yang menggambarkan kondisi integrasi TIK dan $e$-readiness di Asia (UIS, 2014).

Penelitian ini bertujuan untuk mengetahui variabel yang paling berpengaruh dalam penerapan TIK untuk pendidikan di sekolah menggunakan Principal Component Analysis (PCA). PCA merupakan metode unsupervised multivariate analysis yang efektif untuk melakukan ekstraksi data berdimensi tinggi menjadi ruang berdimensi rendah tanpa kehilangan karakteristik data (Aguado, et al., 2008) menggunakan teknik aljabar linier untuk mereduksi dimensi data dengan variabel yang saling berkaitan menjadi data baru dengan variabel yang tidak saling berkaitan yang disebut principal component(Farjo et al., 2013). Principal Component (PC) berisi pecahan informasi/variasi yang tersimpan pada data yang digunakan untuk menghitung seberapa besar korelasi varian(Combes dan Azema, 2013).

\section{Kerangka Teori}

\subsection{Indikator TIK untuk Pendidikan}

Penggunaan TIK untuk pembelajaran di sekolah mampu meningkatkan hasil capaian pembelajaran dengan meningkatkan tingkat kepercayaan diri siswa dan membantu meningkatkan konsentrasi siswa. Adapun yang perlu diperhatikan dalam penggunaan TIK untuk pembelajaran di sekolah antara lain pengaturan jumlah jam belajar dengan TIK, media TIK yang digunakan dan kemampuan guru dalam pemanfaatan TIK (Hussain et al., 2011).

Indikator utama TIK meliputi lima sektor yaitu : 1) Infrastruktur dan akses TIK; 2) Akses dan penggunaan TIK oleh rumah tangga dan individu; 3) Akses dan penggunaan TIK pada bisnis; 4) Sektor TIK dan perdagangan; 5) Akses dan penggunaan TIK pada sektor pendidikan. Indikator akses dan penggunaaan TIK di sektor pendidikan dikembangkan oleh UNESCO Institute for Statistics (UIS) (ITU, 2010). Framework yang digunakan UIS dalam mengembangkan indikator TIK untuk pendidikan diformulasikan dalam bentuk pertanyaan kebijakan kunci yang meliputi domain komitmen politis, infrastruktur, pengembangan guru, kurikulum, penggunaan, partisipasi, skill dan hasil/output, dan dampak yang dihasilkan.

Indikator yang dikembangkan digunakan untuk memonitor perkembangan TIK untuk pendidikan secara global dengan penekanan pada peran utama sekolah sebagai obyek pengumpulan data, dan metode pengumpulan data untuk memonitor akses, penggunan dan hasil pemanfaatan TIK untuk pendidikan (UIS, 2009).

Indikator yang dikembangkan oleh UIS dapat digunakan pada tingkat internasional, nasional, subnasional, dan sekolah. Di tingkat internasional dan nasional, indikator tersebut digunakan untuk memonitor dan mendukung formulasi kebijakan dan pengambilan keputusan. Sedangkan pada tingkat sub-nasional dan sekolah digunakan untuk membandingkan infrastruktur TIK, akses, penggunaan dan hasil pembelajaran. Prinsip utama dalam pemilihan indikator meliputi relevansi kebijakan, metode pengumpulan data yang handal, minimasi beban pengumpulan data dan perbandingan internasional (UIS, 2009). Evolusi kebutuhan informasi pada setiap tahapan implementasi kebijakan nasional dengan perubahan tingkat penetrasi TIK dalam sistem pendidikan yang ada diilustrasikan pada Gambar 1. Indikator TIK untuk pendidikan di sekolah dapat dilihat pada Tabel 1 . 


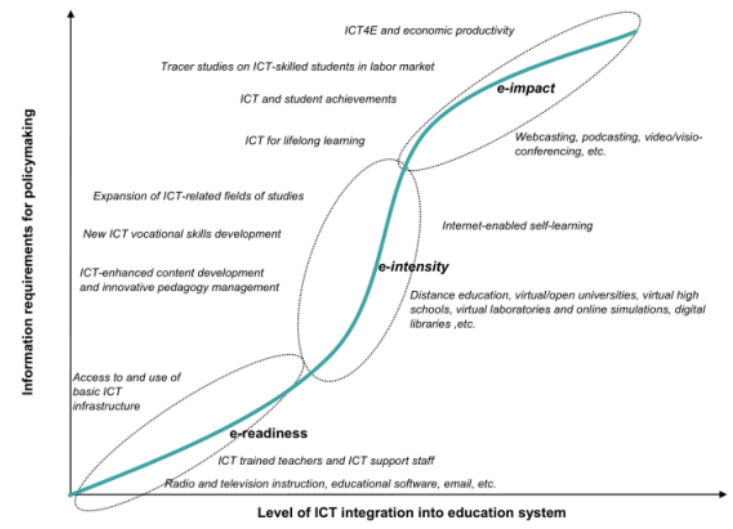

Gambar 1. Kebutuhan Informasi pada Tingkat Penetrasi TIK yang berbeda dalam Sistem Pendidikan (UIS, 2009)

\subsection{Principal Component Analysis (PCA)}

Principal Component Analysis (PCA) merupakan tools analisis data yang bersifat non parametrik untuk mengekstrak informasi yang relevan dari sebuah set data kemudian mereduksi data set yang komplek menjadi dimensi yang lebih rendah (Shlens, 2014). PCA menggunakan teknik aljabar linier untuk mereduksi dimensi data dengan variabel yang saling berkaitan menjadi data baru dengan variabel yang tidak saling berkaitan yang disebut principal component(Farjo et al., 2013).

Principal Component (PCs) berisi pecahan informasi/variasi yang tersimpan pada data yang digunakan untuk menghitung seberapa besar korelasi varian. Jumlah PCs (eigenvector) yang diekstrak sama dengan jumlah variabel yang dianalisa (Farjo et al., 2013). Varian tertinggi terdapat pada PC pertama (Dharmaraj et al., 2006). Set data yang akan direduksi diasumsikan mempunyai noise yang besar, seperti diilustrasikan pada Gambar 2 data signal dan noise ditunjukkan sebagai garis pada diagram. Data yang bergerak sesuai garis lurus adalah data yang baik, sedangkan data yang menyimpang dari garis lurus adalah noise. Dengan demikian PCs dengan nilai varian yang tinggi menggambarkan struktur data yang penting, sedangkan nilai varian yang lebih rendah menunjukkan adanya noise (Shlens, 2014).

PCA mampu menghilangkan redundansi informasi dari set data yang disebabkan karena beberapa variable diukur dengan susunan yang sama/berhubungan. Gambar 3 memberikan ilustrasi kemungkinan terjadinya redundansi data dari dua pengukuran yang terpisah $r_{l}$ dan $r_{2}$. Gambar 3 (a) dan (b) menggambarkan bahwa $r_{1}$ dan $r_{2}$ tidak saling berhubungan, karena $r_{l}$ tidak dapat memprediksi $r_{2}$ dan sebaliknya. Berbeda dengan Gambar 3(c) yang menggambarkan adanya hubungan sangat kuat dan menunjukan redundansi pengukuran yang tinggi. Redundansi dapat dihilangkan menggunakan satu variabel karena $r_{1}$ dapat dihitung dari $r_{2}$ (atau sebaliknya) menggunakan best-fit line (Shlens, 2014).
Tabel 1. Indikator TIK untuk Pendidikan di Sekolah Hasil Adaptasi Indikator UIS 2009

\begin{tabular}{ll}
\hline Komitmen & Kurikulum \\
\hline ED10 & Rata-rata jumlah jam per minggu penggunaan \\
& TIK di kelas sesuai kurikulum per mata pelajaran \\
& (Matematika, Sains, Komputer Dasar, Bahasa, \\
& Seni) \\
ED11 & Rata-rata jumlah jam per minggu penggunaan \\
& TIK di kelas sesuai kurikulum \\
& a. Latihan komputer - software pendidikan \\
& b. Latihan komputer - internet \\
& c. Radio (Pembelajaran Radio interaktif) \\
& d. Televis
\end{tabular}

Infrastruktur

EDR1 Ketersediaan Sumber Daya Listrik Sekolah

ED1 Pemanfaatan Alat Bantu Radio untuk Pembelajaran

ED2 Pemanfaatan Televisi untuk Pembelajaran

ED3 Ketersediaan Fasilitas Telekomunikasi

ED4 Rasio Learner-to-Computer di sekolah untuk pembelajaran dengan alat bantu komputer

ED4BIS Rasio siswa terhadap computer

ED5 Ketersediaan Akses Internet Sekolah (Tipe Akses)

ED25 Rasio Learner-to-Computer yang terhubung dengan internet

ED29 Proporsi ketersediaan komputer untuk tujuan pembelajaran

ED30 Proporsi ketersediaan komputer untuk tujuan administrasi

ED31 Ketersediaan website sekolah

Pengembangan Guru

ED8 Proporsi guru yang mempunyai kualifikasi TIK

ED34 Ketersediaan layanan pendukung TIK

ED35 Proporsi guru yang dilatih melalui program pendidikan jarak jauh berbasis TIK

ED36 Proporsi guru yang mengajar skill komputer dasar/komputasi

ED37 Proporsi guru yang mengajar menggunakan fasilitas TIK

ED38 Proporsi guru terlatih untuk mengajar menggunakan fasilitas TIK

ED39 Rasio learner-to-teacher yang mempunyai skill komputer dasar/komputasi

ED40 Rasio learner-to-teacher yang menggunakan TIK Pemanfaatan untuk mengajar

ED6 Proporsi siswa yang mempunyai akses internet di sekolah

ED41 Proporsi siswa yang berhak menggunakan laboratorium komputer di sekolah untuk pembelajaran

Partisipasi Siswa

ED44 Proporsi siswa yang terdaftar di kelas dengan pembelajaran berbasis TIK

ED45 Proporsi siswa yang terdaftar di kelas dimana skill komputer dasar diajarkan

ED48 Proporsi siswa yang berhasil menyelesaikan pelajaran kemampuan komputer dasar pada akhir tahun ajaran 


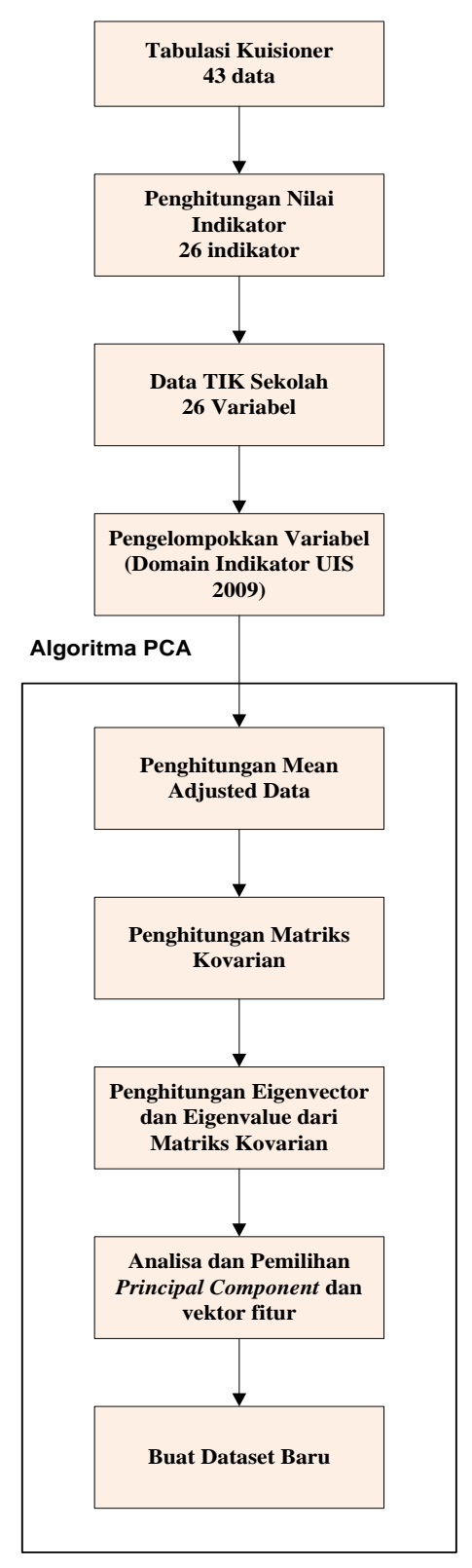

Gambar 2. Prosedur Penelitian

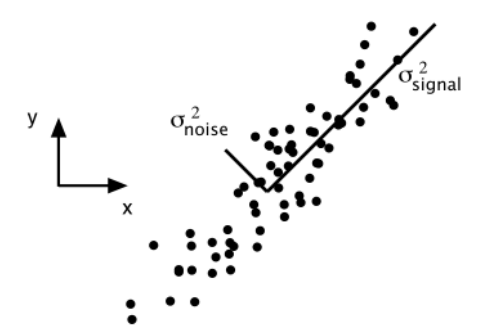

Gambar 3. Ilustrasi noise Data (Shlens, 2014).

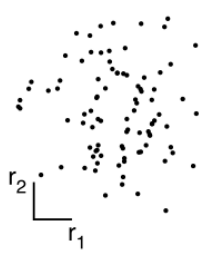

low redundancy

(a)

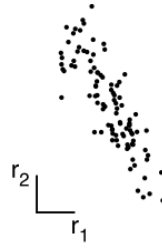

(b)

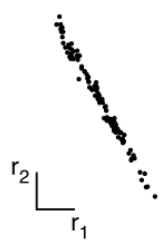

high redundancy

(c)
Gambar 4. Ilustrasi Redundansi Data (Shlens, 2014)

Tahapan proses PCA dijelaskan secara rinci sebagai berikut (Farjo et al., 2013):

1. Menghitung MeanAdjustedData (B) dengan cara mengurangkan setiap nilai data dengan nilai rerata tiap dimensi sehingga mendapatkan data dengan sifat zero-mean.

$$
B=x-\bar{x} \quad \text { dengan } \quad \bar{x}=\frac{\sum_{i=1}^{n} x_{i}}{n}
$$

$x$ mewakili data dan $\bar{x}$ menyatakan rata-rata seluruh sampel data.

2. Menghitung matrik kovarian (C) dengan persamaan:

$$
C=\frac{1}{n-1} B^{\prime} B
$$

dengan B menyatakan MeanAdjusted Data, B' transpose dari matrik $\mathrm{B}$, dan $\mathrm{n}$ adalah jumlah data.

3. Ekstrak nilai eigenvalue dan eigenvector(PC) dari matrik kovarian, dihitung menggunakan persamaan karakteristik:

$$
C-\lambda I=0 \text { dan }(C-\lambda I) x=0
$$

dengan $C$ menyatakan matriks kovarian, $I$ menyatakan matrik indeks, $\lambda$ menyatakan eigenvalue, dan $x$ menyatakan eigenvector.

Eigenvalue menggambarkan jumlah varian yang dihitung oleh eigenvector

4. Urutkan eigenvector berdasarkan nilai eigenvalue yang paling besar

5. Pilih PCs(eigenvector) menggunakan m-method untuk membentuk FeatureVector (matriks yang dibentuk dari eigenvector yang terpilih)

$$
V_{m}=\left[\begin{array}{lllll}
e i g_{1} & e i g_{2} & e i g_{3} & \ldots & e i g_{m}
\end{array}\right]
$$
dengan $\mathrm{V}_{\mathrm{m}}$ menyatakan vektor fitur, eig adalah eigenvector, $m$ menyatakan jumlah PC yang dipilih.

6. Hitung FinalData dengan mengkalikan transpose FeatureVector dengan transpose MeanAdjustedData

$$
D=\left(V_{m}\right)^{T}(B)^{T}
$$

dengan D menyatakan FinalData, $\mathrm{V}_{\mathrm{m}}$ menyatakan vektor fitur dan B menyatakan MeanAdjustedData.

7. FinalData menggambarkan data asli sesuai dengan eigenvector yang dipilih.

\section{Metodologi}

Prosedur penelitian digambarkan pada Gambar 2 . Data hasil pengumpulan kuisioner menggunakan aplikasi Microsoft Office Excel 2007, data hasil 
tabulasi tersebut digunakan untuk menghitung setiap indikator. Hasil penghitungan nilai indikator kemudian disebut sebagai data TIK sekolah dengan 26 variabel. Proses reduksi dimensi diawali dengan pengelompokkan variable berdasarkan domain pada indikator TIK untuk Pendidikan yang dikembangkan oleh UIS tahun 2009, yaitu 5 kelompok, yaitu kurikulum, infrastruktur, pengembangan guru, pemanfaatan, dan partisipasi siswa. Pada masingmasing kelompok kemudian dilakukan reduksi menggunakan PCA untuk menghasilkan komponen utama dengan nilai eigenvalue tertinggi dan mempunyai korespondensi dengan nilai eigenvector yang terbesar. Analisa PC dilakukan untuk mengetahui variabel yang paling berpengaruh di tiap kelompok.

\section{Hasil dan Pembahasan}

\subsection{Hasil Tampilan Aplikasi}

Pada penelitian ini dapat diperoleh data dengan tampilan pada aplikasi tertera pada Gambar 4 berikut ini.

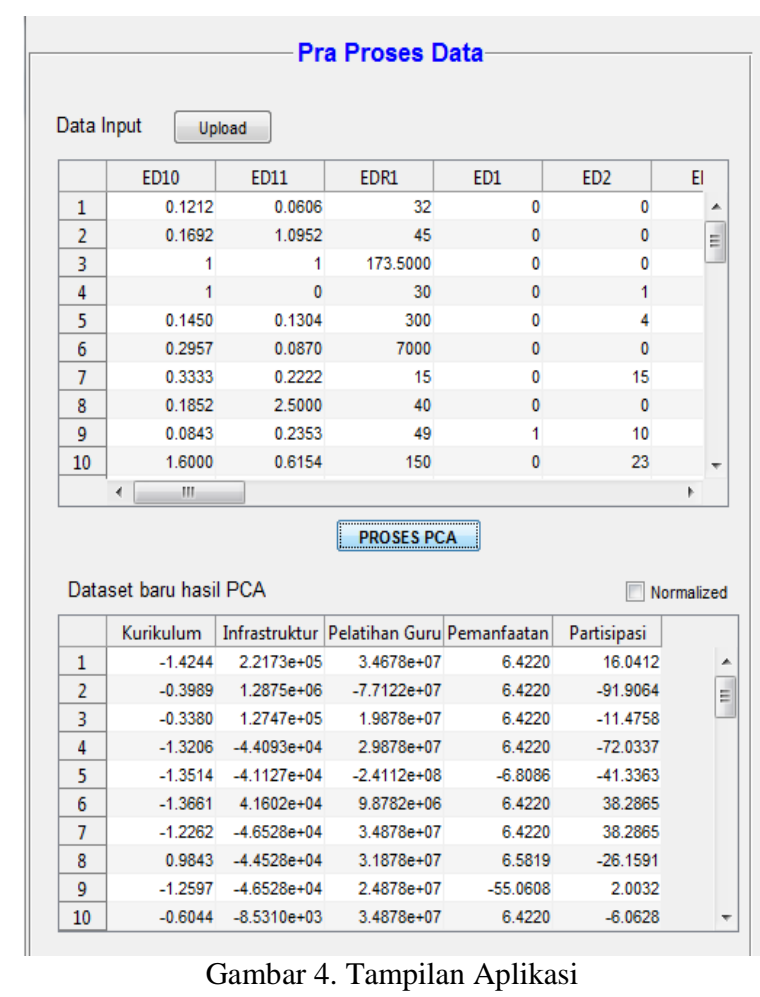

\subsection{Pengelompokkan Variabel}

Data hasil penghitungan indikator yang terdiri dari 26 variabel dibagi menjadi 5 dengan cara mengelompokkan data berdasarkan domain UIS 2009. Masing-masing dataset kelompok kemudian diproses menggunakan algoritma PCA untuk menghasilkan principal component( $\mathrm{PC})$ dengan nilai eigenvalue tertinggi dan mempunyai korespondensi dengan nilai eigenvector yang terbesar.

\subsection{Penentuan PC pada Kelompok Kurikulum}

Berdasarkan hasil penghitungan eigenvalue dataset kelompok kurikulum, menghasilkan PC dengan nilai tertinggi sebesar 13,04 dan mempunyai pengaruh $87,70 \%$ dari keseluruhan data. Analisis eigenvector pada PC1 menjelaskan bahwa rata-rata jumlah jam penggunaan TIK individu (praktikum TIK) di kelas (ED11) mempunyai pengaruh paling besar dibandingkan dengan rata-rata jumlah jam penggunaan TIK untuk mata pelajaran (ED10).

\subsection{Penentuan PC pada Kelompok Infrastruktur}

Berdasarkan hasil penghitungan eigenvalue dataset kelompok infrastruktur, menghasilkan PC dengan nilai tertinggi $3,69 \times 10^{10}$ dan mempunyai pengaruh $99,99 \%$ dari keseluruhan data. Analisis eigenvector pada PC1 menjelaskan bahwa eksistensi sekolah di internet/website sekolah (ED31) mempunyai pengaruh paling besar dibandingkan dengan variabel yang lain.

\subsection{Penentuan PC pada Kelompok Pengembangan Guru}

Berdasarkan hasil penghitungan eigenvalue dataset kelompok pengembangan guru, menghasilkan $\mathrm{PC}$ dengan nilai tertinggi $2,32 \times 10^{15}$ dan mempunyai pengaruh $100 \%$ dari keseluruhan data. Analisis eigenvector pada PC1 menjelaskan bahwa ketersediaan layanan pendukung TIK (ED34) mempunyai pengaruh paling besar dibandingkan dengan variabel yang lain.

\subsection{Penentuan PC pada Kelompok Pemanfaatan}

Berdasarkan hasil penghitungan eigenvalue dataset kelompok pemanfaatan, menghasilkan PC dengan nilai tertinggi 404,54 dan mempunyai pengaruh $82,72 \%$ dari keseluruhan data. Analisis eigenvector pada PC1 menjelaskan bahwa jumlah siswa yang menggunakan laboratorium komputer di sekolah untuk pembelajaran (ED41) mempunyai pengaruh paling besar dibandingkan dengan variabel yang lain.

\subsection{Penentuan PC pada Kelompok Partisipasi Siswa}

Berdasarkan hasil penghitungan eigenvalue dataset kelompok partisipasi siswa, menghasilkan PC dengan nilai tertinggi 1871,10 dan mempunyai pengaruh 50,95\% dari keseluruhan data. Analisis eigenvector pada PC1 menjelaskan bahwa jumlah siswa yang berpartisipasi dalam program skill komputer dasar (ED45) mempunyai pengaruh paling besar dibandingkan dengan variabel yang lain.

\subsection{Pembuatan Data Set Baru Hasil Reduksi}

Setelah PC tiap kelompok ditentukan, maka dataset baru tiap kelompok dibuat dengan cara mengkalikan transpose eigenvector yang mempunyai variansi maksimal dengan transpose dari adjusted data. Hasil reduksi data dari 26 variabel menjadi 5 
dimensi baru yang merepresentasikan data tiap kelompok.

\section{Kesimpulan}

Hasil dari penelitian ini memberikan informasi variabel yang paling berpengaruh di tiap kelompok. Pada kelompok kurikulum, variabel yang paling berpengaruh adalah Rata-rata jumlah jam penggunaan TIK individu, pada kelompok infrastruktur variabel eksistensi sekolah di internet melalui website sekolah, kelompok pengembangan guru variabel presentase siswa yg menggunakan lab komputer utk pembelajaran dan kelompok partisipasi siswa variabel presentase siswa yg mengikuti mata pelajaran skil komputer dasar. Data hasil reduksi tersebut kemudian dapat digunakan sebagai input analisis data seperti pengelompokkan yang tertera pada Tabel 2 berikut ini.

Tabel 2. Hasil Analisis Principal Component pada Tiap Kelompok Variabel

\begin{tabular}{|c|c|c|c|}
\hline $\begin{array}{c}\text { Variabel yang paling } \\
\text { berpengaruh }\end{array}$ & $\begin{array}{l}\text { Eigenvalue } \\
\text { tertinggi }\end{array}$ & $\begin{array}{c}\% \\
\text { Komulatif }\end{array}$ & $\begin{array}{c}\text { Nilai } \\
\text { Korelasi }\end{array}$ \\
\hline $\begin{array}{l}\text { Kurikulum: } \\
\text { ED11 Rata-rata jumlah } \\
\text { jam penggunaan TIK } \\
\text { individu (praktikum } \\
\text { TIK) } \\
\end{array}$ & 13,04 & 87,70 & 0,983 \\
\hline $\begin{array}{l}\text { Infrastruktur: } \\
\text { ED31 Eksistensi } \\
\text { sekolah di internet } \\
\text { melalui website sekolah }\end{array}$ & $3,69 \mathrm{E}+10$ & 99,99 & 1 \\
\hline \begin{tabular}{lr}
\multicolumn{2}{l}{ Pengembangan Guru: } \\
ED34 & Ketersediaan \\
layanan & pendukung \\
TIK & \\
\end{tabular} & $2,32 \mathrm{E}+15$ & 100 & 0,877 \\
\hline $\begin{array}{l}\text { Pemanfaatan: } \\
\text { ED41 Proporsi siswa } \\
\text { yang menggunakan } \\
\text { labortorium komputer } \\
\text { untuk pembelajaran }\end{array}$ & $2,32 \mathrm{E}+15$ & 100 & 1 \\
\hline $\begin{array}{l}\text { Partisipasi Siswa: } \\
\text { ED45 Proporsi } \\
\text { yang mengikuti mata } \\
\text { pelajaran } \\
\text { komputer dasar }\end{array}$ & 1871,10 & 50,95 & 0,722 \\
\hline
\end{tabular}

\section{Ucapan Terima Kasih}

Ucapan terimakasih penulis tujukan kepada Kementerian Pendidikan dan Kebudayaan sebagai fasilitator dan pemberi dana penelitian.

\section{Daftar Pustaka}

Aoki, H., Kim, J. and Lee, W., 2013. Propagation \& level: Factors influencing in the ICT composite index at the school level, Computers \& Education 60, 310-324.

Dharmaraj, S., Hossain, MA., Zhari, S., Harn, GL., Ismail, Z., 2006. The Use of Principal Component Analysis and Self-Organizing Map to Monitor Inhibition of Calcium Oxalate Crystal Growth by Orthosiphon Stamineus Extract, Chemometrics and Intelligent Laboratory Systems 81, pp. $21-28$.

Farjo, J.,Assi, RA., Masri, W., Zaraket, F., 2013. Does Principal Component Analysis Improve ClusterBased Analysis?, IEEE Sixth International Conference on Software Testing, Verification and Validation Workshops 52, pp. 400-403.

Hussain, A.J., Morgan, S. and Al-Jumeily, D., 2011. How does ICT affect teachings and learning within school education. Proceedings - 4th International Conference on Developments in eSystems Engineering, DeSE 2011, pp.250-254.

International Telecommunication Union, 2010. Core ICT Indicator, Switzerland.

Kemdikbud, 2013. Peraturan Menteri Pendidikan dan Kebudayaan No. 99 Tahun 2013 tentang Tata Kelola Teknologi Informasi dan Komunikasi di Lingkungan Kemdikbud, pp.1-4.

Pinheiro, M.M \& Simoes, D., 2012. Constructing Knowledge: An Experience of Active and Collaborative Learning in ICT Classrooms. TOJET, 11 pp.382-389.

Sánchez, J., Salinas, Á. \& Harris, J., 2011. Education with ICT in South Korea and Chile. International Journal of Educational Development, 31, pp.126148.

Shlens, J., A Tutorial on Principal Component Analysis, 2014, Google Research

UNESCO Institute for Statistics, 2009. Guide to Measuring Information and Communication Technologies (ICT) in Education, Canada.

UNESCO Institute for Statistics, 2014. ICT in Education in ASIA : A comparative analysis of ICT integration and $e$ - readiness in schools across Asia, Canada.

Umar, I.N and Yusoff, M.T.M, 2014. A Study on Malaysian teacher's level of ICT skills and practices, and its impact on teaching and learning, Procedia - Social and Behavioral Sciences, 116, pp. 979-984.

Valcarel, A.G, Basilotta, V. and Salamanca, C.L., 2014. ICT in Collaborative Learning in the Classrooms of Primary and Secondary Education, Comunicar- Media Education Research Journal,42 pp. 65-74. 